\title{
The association between occupational stress and depressive symptoms and the mediating role of psychological capital among Chinese university teachers: a cross-sectional study
}

\author{
Xue Shen, Yi-Long Yang, Yang Wang, Li Liu, Shu Wang and Lie Wang*
}

\begin{abstract}
Background: Depression is a major public health problem that affects both individuals and society. Previous studies report that university teachers are particularly susceptible to high levels of occupational stress and depressive symptoms. The aims of this study were to explore the association between occupational stress and depressive symptoms in a group of university teachers, and assess the mediating role of psychological capital between these variables.

Methods: A cross-sectional study was performed between November 2013 and January 2014. Teachers from six universities were randomly sampled in Shenyang. The Center for Epidemiologic Studies Depression Scale, effort-reward imbalance scale, and psychological capital questionnaire (PCQ-24), as well as questions about demographic and working factors, were administered in questionnaires distributed to 1,500 university teachers. Completed questionnaires were received from 1,210 participants. Hierarchical linear regression analysis was used to examine the mediating role of psychological capital.
\end{abstract}

Results: In the present study, 58.9\% (95\% Cl (Confidence Intervals): $56.1 \%$ to $61.7 \%$ ) of university teachers had a CES-D score equal to or above the cut-off of 16. Both effort-reward ratio (ERR) and scores of over-commitment were positively associated with depressive symptoms, whereas psychological capital was negatively associated with depressive symptoms among university teachers. Psychological capital partially mediated the relationship between occupational stress and depressive symptoms.

Conclusions: Among Chinese university teachers, occupational stress may be a risk factor for depressive symptoms, whereas psychological capital might be protective against depressive symptoms. Our results suggest that college administrators could support the development of psychological capital in their staff to alleviate depressive symptoms.

Keywords: Depressive symptoms, Psychological capital, Occupational stress, University teachers

\section{Background}

Depression is a disease that can affect anyone, and is defined as feelings of guilt, worthlessness, helplessness and hopelessness. Its symptoms include loss of appetite, depressed mood, or disturbed sleep [1]. According to the World Health Organization (WHO), depression will likely be the second leading cause of disability worldwide by 2020 [2]. Depression affects a relatively large proportion

\footnotetext{
* Correspondence: liewang@mail.cmu.edu.cn

Department of Social Medicine, School of Public Health, China Medical University, No.77 Puhe Road, Shenyang North New District, Shenyang, Liaoning, China
}

of individuals. In Korea, the prevalence of depressive symptoms is reported as $26.1 \%$ for men and $28.7 \%$ for women [3]. Similarly, a study in China reported that nearly one third of the general population suffered from depressive symptoms [4]. Depression rates may differ amongst different professions, with some occupations having increased risk. In America, 12.2\% of Iowa farmers reported high level of depressive symptoms [5]. Identifying at risk occupational groups is important because previous studies indicate that depression can increase the risk of obesity, suicidal ideation, burnout, and job turnover [6-8]. 
It may also negatively affect job satisfaction, quality of life, and well-being $[9,10]$.

In China, rapid development of higher education and expansion of enrollment in universities has meant that the competition between colleges and universities is becoming increasingly intense. Teachers are put under pressure with substantial teaching responsibilities and scientific research work. This pressure may contribute to mental health problems. Recently, exploring factors associated with depression has become an expanding area of research. Studies suggest that workload and an adverse psychological environment at work significantly predict depression among teachers $[7,11,12]$. Moreover, studies in various populations suggest that social anxiety, work-related stress, and stressful life events may contribute to depression [13-15].

Occupational stress has therefore come to be considered by many as a risk factor for depressive symptoms [16-18].

Occupational stress can be assessed using the effortreward imbalance model (ERI), which focuses on reciprocity of extrinsic effort, intrinsic effort, and reward [19]. Kinman and colleagues reported that high effort and low rewards within the ERI model significantly predicted negative outcomes, including psychological distress, physical symptoms, and low job satisfaction among UK university employees [20]. Teaching may be a profession that is particularly associated with high stress [8,21], as it requires speedy decision-making, and balancing the demands of and relationships with superiors, colleagues, and students. Moreover, there are additional pressures that include promotion, performance appraisal, and redundancy. This is reflected in a study of 17 Australian universities, where researchers found that $43 \%$ of academic staff and $37 \%$ of non-academic staff experienced occupational stress [22].

Teachers in every culture consider the individual differences of their students, teaching each according to their ability to learn. Thus, teachers are tasked with the important duty of aiding in the healthy development of students, as well as being required to provide quality intellectual education. However, teachers in China have additional pressure from the cultural adherence to Confucian principles. There are extremely strong social expectations that every teacher follow the philosophy of Confucius.

Some scholars have attempted to identify positive resources for combating occupational stress, such as perceived organizational support and psychological capital (PsyCap) [23,24]. PsyCap is proposed as a measurable highorder construct, comprising four state-like psychological resources: self-efficacy, hope, optimism, and resilience [25]. According to Luthans and colleagues, PsyCap goes beyond human capital, social capital, and financial capital, and can be measured, developed, and leveraged with various desirable results [26]. Specifically, when employees have high PsyCap, they are equipped with extra resources to handle their work tasks, expect good things to happen, quickly "bounce back" after setbacks, and are more hopeful about negative situations. Positive PsyCap, as an emerging core construct, has attracted the attention of many researchers in various fields, including private businesses (relating to their employees), medicine (relating to both staff and patients), and education (relating to students) [10,16,25,27]. Previous research has shown that PsyCap is positively associated with job performance, job satisfaction, and well-being [25,28], but negatively associated with depression, burnout, and staff turnover $[16,24,29]$. According to Luthans and colleagues, PsyCap plays a mediating role in the relationship between a supportive organizational climate and staff performance [30]. Lin and colleagues reported that PsyCap was a mediator between perceived organizational support and job burnout among employees of international tourist hotels in China [31]. Furthermore, Cheung and colleagues have suggested that PsyCap is a moderator between emotional labor (the requirement that employees display appropriate emotions to clients and others) and job satisfaction [32]. Therefore, previous research suggests that PsyCap may be particularly significant in the development of depression in occupational settings. Hence, we herein examine the potential mediating effects of PysCap on the posited association between occupational stress and depressive symptoms among university teachers.

The literature discussed above suggests that occupational stress and PsyCap are associated with depressive symptoms. However, there is a lack of understanding of potential variables that may reduce the impact of occupational stress on depressive symptoms. The findings of Liu and colleagues suggest that PsyCap plays a mediating role in the relationship between occupational stress and depressive symptoms among Chinese female physicians. Therefore, we hypothesize that PsyCap might have the mediating effect on the relationship between occupational stress and depressive symptoms among Chinese university teachers. This has not previously been investigated.

The main objectives of our study are to a) assess the prevalence of depressive symptoms among Chinese university teachers; b) explore associations between occupational stress, PsyCap, and depressive symptoms; and c) examine the mediating role of PsyCap in the relationship between occupational stress and depressive symptoms.

\section{Methods}

\section{Research design and sample}

A cross-sectional survey of health status among university teachers was conducted from November 2013 to January 2014 in Shenyang city, the capital of Liaoning province and the center of higher education in Northeast China. Universities in Liaoning province are mainly located in 
Shenyang city, with the total number of full-time teachers reaching 24,888 (according to Shenyang Statistical Information Net, 2013) [33]. Six universities (two comprehensive universities and four specialized universities focusing on medicine and architecture) were randomly selected and $25 \%$ of full-time teachers were randomly sampled from each selected university. Self-administered questionnaires were distributed to 1,500 teachers after obtaining written informed consent, and answers were received anonymously. A total of 1,210 effective responses were obtained (effective response rate: $80.7 \%$ ). This study was approved by the Committee on Human Experimentation of China Medical University, and study procedures were in accordance with ethical standards.

\section{Demographic and working characteristics}

Demographic characteristics collected included gender, age, marital status, education, and professional position. Marital status was categorized as single/widowed/divorced and married/cohabiting. Education was categorized as bachelor/master/doctor. Professional position was classified into assistant/lecturer/associate professor/professor. Participants were categorized as having chronic disease if they responded 'yes' to ever receiving a diagnosis of any listed disease (e.g., hypertension, diabetes, gout, cardiovascular disease, chronic gastritis, back pain, and arthritis).

\section{Measurement of depressive symptoms}

Depression was measured by the Chinese version of the Center for Epidemiologic Studies Depression Scale (CES-D) [1]. This scale consists of 20 items related to characteristic symptoms and behaviors of depression, with each item rated from 0 to 3 . The CES-D has been widely used in Chinese populations with good reliability and validity $[4,34]$. The total score ranges from 0 to 60 , and CES-D $\geq 16$ indicates that respondents may be more likely to be depressed [35]. In the present study, Cronbach's alpha was 0.891. Additionally, confirmatory factor analysis (CFA) on a single factor model with twenty scale items was conducted to support validity of the depression questionnaire among university teachers $\left(\mathrm{X}^{2} / \mathrm{df}=3.925, \mathrm{CFI}=0.959, \mathrm{GFI}=0.951, \mathrm{TLI}=0.950\right.$ and RMSEA $=0.049$ ).

\section{Measurement of occupational stress}

We used the effort-reward imbalance (ERI) model to assess occupational stress experienced by teachers. The Chinese version of the ERI questionnaire, developed by Professors Li and Yang, is considered a reliable and valid instrument for measuring psychosocial stress at work [36]. The 23-item ERI questionnaire comprises three subscales: effort (6 items), reward (11 items) and over-commitment (6 items). Responses to "effort" and "reward" items were scored on a five-point scale, while responses to "over- commitment " items were scored from 1 to 4 . Effortreward ratio (ERR) was calculated using a predefined algorithm that quantifies the degree of mismatch between high cost and low gain, with a correction factor of 0.5454 [37]. An ERR ratio greater than 1.0 indicates that the individual's reward was not matched by the effort he/ she made. An ERR ratio of less than 1.0 indicates the opposite. In this study, Cronbach's alpha coefficients for effort, reward, and over-commitment subscales were $0.870,0.898$, and 0.725 , respectively.

\section{Measurement of psychological capital (PsyCap)}

PsyCap was measured with the Chinese version of the 24-item Psychological Capital Questionnaire (PCQ) [25]. The PCQ consisted of four dimensions: self-efficacy, hope, resilience, and optimism. Each of the four dimensions comprised six items, rated from 1 (strongly disagree) to 6 (strongly agree). Higher values indicated higher levels of experienced PsyCap. The PCQ has been widely used, and demonstrates adequate reliability and validity in multiple samples [25,38].

In the present study, a confirmatory factor analysis (CFA) was performed to check for the fit of the scales with the data. We began by fitting this model with six items for each facet (i.e., self-efficacy, hope, resilience, and optimism) and then fit each of the four dimensions to the higher-order PsyCap. The second-order factor model showed a good fit with the data $\left(\mathrm{X}^{2} / \mathrm{df}=3.671, \mathrm{GFI}=0.944\right.$, $\mathrm{CFI}=0.971$, TLI $=0.964$, and RMSEA $=0.047$ ). For the total scale, the Cronbach's alpha coefficient was 0.949 . Cronbach's alpha coefficients of self-efficacy, hope, resilience, and optimism were $0.905,0.904,0.818$ and 0.745 , respectively.

\section{Statistical analysis}

Differences in continuous variables were examined using the Student's t-test and one-way ANOVA, and the significance level was set at $\mathrm{p}<0.05$ (two-tailed). For the prevalence of depressive symptoms, participants scoring 16 or higher were defined as depressed. Pearson's correlation analysis was used to assess correlations between study variables. Hierarchical linear regression analysis was used to explore the effects of groups of independent variables on depressive symptoms, and the fit of the model was assessed with $\mathrm{R}^{2}$.

We tested the mediating role of PsyCap according to the theory of Baron and Kenny [39]. Accordingly, the following conditions should be satisfied: (1) the independent variable (ERI) is significantly associated with the dependent variable (depressive symptoms); (2) the independent variable is significantly associated with the mediator (PsyCap); (3) the mediator is significantly associated with the dependent variable after controlling for the effect of the independent variable. If the effect of the independent variable on the 
dependent variable shrinks upon the addition of the mediator to the model it is a partial mediator. If the independent variable does not affect the dependent variable when the mediator is added to the model then full mediation is established.

All study variables were centralized before being entered into the hierarchical linear regression model for the purpose of avoiding multicollinearity [40]. In Block 1, the control variables were added, including gender, age, marital status, and education. In Block 2, the independent variable (ERI) was added. In Block 3, the mediator (PsyCap) was added. The Sobel test was performed to calculate the significance of the mediating effect. All analyses were conducted using SPSS 17.0 for Windows. Statistical significance was defined as $\mathrm{p}<0.05$ (two-tailed).

\section{Results}

Participant characteristics

Table 1 shows the basic characteristics of the participants and the prevalence of depressive symptoms within the demographic categories. Respondents included 513 men

Table 1 Demographic characteristics and differences in depressive symptoms

\begin{tabular}{|c|c|c|c|}
\hline Variables & $\mathbf{N}$ & $\%$ & CES-D (Mean \pm SD) \\
\hline \multicolumn{4}{|l|}{ Gender } \\
\hline Males & 513 & 42.4 & $18.63 \pm 9.78$ \\
\hline Females & 697 & 57.6 & $18.37 \pm 9.11$ \\
\hline \multicolumn{4}{|l|}{ Age } \\
\hline$\leq 30$ & 174 & 14.4 & $16.37 \pm 8.60$ \\
\hline $31-40$ & 565 & 46.7 & $19.48 \pm 8.95^{* *}$ \\
\hline $41-50$ & 367 & 30.3 & $18.12 \pm 10.14$ \\
\hline$>50$ & 104 & 8.6 & $17.84 \pm 9.70$ \\
\hline \multicolumn{4}{|l|}{ Marital status } \\
\hline Single/widow/separated & 186 & 15.4 & $17.72 \pm 8.26$ \\
\hline Married/cohabitation & 1024 & 84.6 & $18.62 \pm 9.59$ \\
\hline \multicolumn{4}{|l|}{ Education } \\
\hline Bachelor & 168 & 13.9 & $19.47 \pm 10.64$ \\
\hline Master & 557 & 46.0 & $18.77 \pm 8.95$ \\
\hline Doctor & 485 & 40.1 & $17.80 \pm 9.42$ \\
\hline \multicolumn{4}{|l|}{ Professional position } \\
\hline Assistant & 105 & 8.7 & $17.82 \pm 9.23$ \\
\hline Lecturer & 493 & 40.7 & $19.11 \pm 8.97$ \\
\hline Associate professor & 445 & 36.8 & $19.19 \pm 9.84^{* *}$ \\
\hline Professor & 167 & 13.8 & $15.17 \pm 8.86$ \\
\hline \multicolumn{4}{|l|}{ Chronic disease } \\
\hline No & 739 & 61.1 & $16.97 \pm 8.74$ \\
\hline Yes & 471 & 38.9 & $20.85 \pm 9.90^{* *}$ \\
\hline
\end{tabular}

CES-D: the Center for Epidemiologic Studies Depression Scale. $* * p<0.01$ (two-tailed).
(42.4\%) and 697 women (57.6\%), whose ages ranged from 24 to 62 years (mean 39.15 years, SD $=8.02$ ). The prevalence of depressive symptoms was 58.9\% (95\% CI: $56.1 \%$ to $61.7 \%$ ). Occupational stress (ERR $>1$ ) was observed in $22.3 \%$ of university teachers. Teachers aged between 31 and 40 years old had significantly higher levels of depressive symptoms than other age groups $(\mathrm{p}<0.05)$. Those with chronic disease had higher CES-D scores than those without $(p<0.05)$. Professors had lower CES-D scores than all others $(\mathrm{p}<0.05)$. Differences in CES-D scores for gender, marital status, and education categories were not statistically significant $(\mathrm{p}>0.05)$.

\section{Correlations between study variables}

The means, standard deviations, and Pearson correlation analyses of continuous variables (age, CES-D, ERR, overcommitment, and PsyCap) are presented in Table 2. Results revealed that all variables were significantly correlated with each other except age (which only correlated with PsyCap), and these correlations were in the expected directions. Specifically, ERR and over-commitment were positively correlated with depressive symptoms, and negatively correlated with PsyCap. PsyCap was negatively correlated with depressive symptoms.

\section{The mediating role of PsyCap in the association between} occupational stress and depressive symptoms

Results of the hierarchical linear regression analysis to explore the mediating role of PsyCap are provided in Table 3. After adjustment for gender, age, marital status, and educational level, the independent variables ERR and over-commitment were added in block 2, before PsyCap was entered into block 3 of the model. The results revealed that both ERR and over-commitment were positively associated with depressive symptoms, explaining $22.6 \%$ of the variance in the data. However, PsyCap was negatively associated with depressive symptoms. Standardized regression coefficients $(\beta)$ reduced with the inclusion of PsyCap, accounting for an additional $7.6 \%$ of the variance $(\mathrm{p}<0.05)$. Therefore, PsyCap played a partial

Table 2 Means, standard deviations (SD), and correlations between continuous variables

\begin{tabular}{llllllll}
\hline Variables & Mean & SD & $\mathbf{1}$ & $\mathbf{2}$ & $\mathbf{3}$ & $\mathbf{4}$ & $\mathbf{5}$ \\
\hline 1. Age & 39.15 & 8.02 & 1 & & & & \\
2. CES-D & 18.48 & 9.4 & -0.009 & 1 & & & \\
$\begin{array}{l}\text { 3. ERR } \\
\text { 4. Over- }\end{array}$ & -0.18 & 0.25 & 0.041 & $0.463^{* *}$ & 1 & & \\
$\quad$ & 14.42 & 3.71 & 0.011 & $0.382^{* *}$ & $0.654^{* *}$ & 1 & \\
$\begin{array}{l}\text { 5. PsyCap } \\
\text { Comitment }\end{array}$ & 4.26 & 0.78 & $0.077^{* *}$ & $-0.461^{* *}$ & $-0.442^{* *}$ & $-0.326^{* *}$ & 1
\end{tabular}

CES-D: the Center for Epidemiologic Studies Depression Scale; ERR: effort-reward ratio.

PsyCap: psychological capital.

${ }^{* *} p<0.01$ (two-tailed). 
Table 3 Results of the hierarchical linear regression analysis

\begin{tabular}{llll}
\hline Variables & \multicolumn{3}{l}{ Depressive symptoms } \\
\cline { 2 - 4 } & Block 1 $(\boldsymbol{\beta})$ & Block 2 $(\boldsymbol{\beta})$ & Block 3 $(\boldsymbol{\beta})$ \\
\hline Gender & -0.025 & -0.045 & $-0.054^{*}$ \\
Age & -0.021 & -0.026 & 0.001 \\
Marital status & 0.048 & -0.02 & -0.036 \\
Dummy_e1 & 0.054 & 0.04 & 0.001 \\
Dummy_e2 & $0.066^{*}$ & $0.072^{* *}$ & 0.031 \\
ERR & & $0.372^{* *}$ & $0.242^{* *}$ \\
Over-commitment & & $0.148^{* *}$ & $0.135^{* *}$ \\
PsyCap & & & $-0.314^{* *}$ \\
F & 1.578 & $52.088^{* *}$ & $67.085^{* *}$ \\
Adjusted R & 0.002 & 0.228 & 0.304 \\
$\Delta R^{2}$ & 0.007 & $0.226^{* *}$ & $0.076^{* *}$ \\
\hline
\end{tabular}

Dummy_e1: Master vs. Doctor; Dummy_e2: Bachelor vs. Doctor; ERR: effort/ reward ratio; PsyCap: psychological capital.

${ }^{*} p<0.05,{ }^{* *} p<0.01$ (two-tailed).

$R^{2}$ (R-squared, the coefficient of determination): percentage of the sample response variation in dependent variable that is explained by the independent variable.

mediating role in the association of depressive symptoms with ERR (from $\beta=0.372$ to $\beta=0.242$; Sobel test, $\mathrm{z}=$ 9.73, $\mathrm{p}<0.001$ ) and over-commitment (from $\beta=0.148$ to $\beta=0.135$; Sobel test, $\mathrm{z}=9.24, \mathrm{p}<0.001$ ).

\section{Discussion}

The present study explored the associations between occupational stress, PsyCap, and depressive symptoms, and further examined the mediating role of PsyCap. A large sample of teachers from comprehensive and specialized universities was studied, with a high response rate of $80.6 \%$. The ratio of male to female participants was $1: 1.36$, which was similar to the value (1:1.3 to $1: 1.4)$ obtained in other studies of university teachers in China [21,41,42]. Thus, our study population seems to be representative and supports generalizations made from the study.

We found a total prevalence of depressive symptoms of $58.9 \%$, which is much higher than that reported in Korean employees (26.1\% for men and $28.7 \%$ for women) [3], French nurse managers (33\%) [43], and a Chinese general population sample (33.3\%) [4]. However, it is similar to that of Chinese male correctional officers (61.4\%) [44], and lower than that of Chinese doctors (65.3\%) [45]. Therefore, our results support the assertion that Chinese university teachers might suffer from high rates of depressive symptoms. It is possible that the transformation of the education system and the strict management system of Chinese universities places an immense pressure on university staff in China, which could result in depressive symptoms $[9,46]$. Further cultural pressures, such as traditional Chinese thought (Confucianism), may instill particularly high expectations on teachers from parents and society. They are crucially responsible to impart both moral and intellectual knowledge, and are required to continuously absorb new knowledge to keep up with the high pace of modern technological information. Some teachers might become burned out, unable to cope with so much pressure, and so fall into a state of depression. Our results suggest that there is a great need for college administrators to develop and implement effective measures to alleviate teachers' depressive symptoms and improve their mental health.

Additionally, our study found that both ERR and overcommitment were positively correlated with depressive symptoms, which is consistent with previous findings $[10,47]$. Occupational stress has been identified as a risk factor for depressive symptoms as it may influence mental health, quality of life, and job satisfaction $[9,11,48]$. In the present study, $22.3 \%$ of university teachers were categorized as experiencing occupational stress (ERR score $>1$ ), which is lower than reported for UK university employees (49\%) [49] and teachers in New Zealand (26\%) [50]. Various reasons for the experience of occupational stress have been suggested. Gillespie and colleagues reported that notable sources of stress for university staff included lack of recognition and reward [46]. Abouserie stated that university academic staff members were required to fulfill many competing responsibilities, such as teaching, researching, attending seminars, seeking funding, and writing papers, and $14.7 \%$ of the sample studies fell into the serious stress categories [51]. For university teachers, the level of occupational stress may affect their work efficiency and interpersonal relationships. It may be easy for them to develop a low mood, which to some extent develops into depressive symptoms. In addition, our results revealed that occupational stress was negatively correlated with PsyCap, which motivated us to explore the indirect effect of occupational stress in predicting depressive symptoms. Together, our results encourage further research and the development of preventative techniques to alleviate occupational stress and depressive symptoms among university teachers.

PsyCap is an important concept of organizational behavior, and is considered as a positive resource to combat destructive emotions, stress, burnout, and work-family conflict $[25,52,53]$. Consistent with this, in the present study PsyCap was found to be negatively associated with depressive symptoms among Chinese university teachers. Teachers with higher levels of PsyCap might have more confidence and exert greater effort in the pursuit of success (self-efficacy), preserve the will to accomplish a teaching task or goal (hope), bounce back from adversity or failure with positive psychological capacity (resilience), and have positive expectations and attributes regarding outcomes (optimism) [25]. Our results further support the 
suggestion that PsyCap might be a positive psychological resource for teachers to relieve depressive symptoms.

Besides providing additional support for previous findings, the major contribution of our findings is to highlight that occupational stress might affect risk for depressive symptoms in university teachers via a mediating mechanism of PsyCap. In other words, teachers who faced more occupational stress would be more likely to experience lower levels of PsyCap, which in turn would lead to higher levels of depressive symptoms. Empirical investigation shows that PsyCap can be developed using web-based training interventions [54,55]. Importantly, there is a great need for college administrators to support the development of PsyCap, to reduce occupational stress and improve quality of life among university teachers.

Our findings have theoretical and practical implications for human resources management and performance management. In theory, the present study revealed that PsyCap might be a positive resource for combating occupational stress and depressive symptoms. PsyCap is a core construct that organizations can invest in and develop in their workforce to achieve veritable, sustained growth and performance [30]. Practically, our results should highlight to college administrators the high prevalence of depression in university teachers. There is an urgent need for them to ensure a balance between effort and reward, establish fair performance appraisal systems, and improve social support systems and work environments. Furthermore, our study provides a new perspective for researchers to integrate the positive psychological resources of self-efficacy, hope, optimism, and resilience to relieve depressive symptoms. To improve self-efficacy, college administrators should provide more opportunities for teachers to develop their professional skills and career interests, and construct fair systems of rewards and punishment to boost the confidence of teachers. To enhance hope amongst teachers, college administrators should help staff formulate reasonable development goals, dividing large goals into manageable units and encouraging them to consider multiple pathways to accomplish each subgoal. For instance, small-group discussion may be an effective method of problem solving [56]. In this way, teachers' hope can be increased, which in turn might enhance the level of self-efficacy. To improve optimism, supervisors should motivate employees to attribute positive events to personal, permanent, and pervasive causes, interpret negative events in terms of external, temporary, and situation-specific factors, and to seek available opportunities [57]. When employees are confident that they can identify and plan to overcome obstacles their expectations of achieving goals is increased. As for resilience, positive emotions have been empirically shown to enhance resilience in the face of negative events. College administrators should help teachers make plans to solve problems and overcome obstacles with available resources [55,58]. Furthermore, the psychological capital intervention (PCI) training model has been developed and used for online participants in developing PsyCap [54,59].

Several limitations of the present study must be taken into consideration when interpreting the results. First, this study mainly relied on self-report of participants, which risks response bias from negative affect or social desirability. Second, the list of potential diseases was rather limited. We enumerated several kinds of common chronic diseases, but some diseases such as addictions were not assessed. Third, generalizations from our data should be made with caution since the sample comprised only a small proportion of all teachers in China, and so may not be representative of all Chinese teachers or of teachers in other countries. Fourth, we only explored associations between occupational stress, PsyCap, and depressive symptoms, and examined differences in basic demographic variables. Other factors associated with depressive symptoms should be investigated in further research. Finally, as this study was cross-sectional, we are unable to draw conclusions about cause and effect. Future studies could incorporate a longitudinal design to increase the power of the findings. Indeed, we must acknowledge that reverse causation may explain the results with depressive symptoms determining levels of PsyCap and ERI (depressive symptoms-PsyCap-ERI). This model deserves further research attention.

\section{Conclusions}

In our sample of Chinese university teachers, there was a high prevalence of depressive symptoms (score of 16 or above on the CES-D). Both extrinsic stress (ERR) and intrinsic stress (over-commitment) were positively associated with depressive symptoms, whereas PsyCap was negatively associated with depressive symptoms. PsyCap partially mediated the effect of occupational stress on depressive symptoms. Since PsyCap can be measured and developed, investing interventions to enhance PsyCap may provide new approaches to improve mental health and work efficiency amongst teachers.

\section{Abbreviations}

CES-D: The center for epidemiologic studies depression scale; PsyCap: Psychological capital; ERI: Effort-reward imbalance; ERR: Effort-reward ratio; Cl: Confidence interval.

\section{Competing interests}

The authors declare that they have no competing interests.

\section{Authors' contributions}

XS contributed to study design, questionnaire survey, data input, drafting, and revising the manuscript. YLY assisted in data collection and analyses, and drafting the manuscript. YW and LL participated in the design, interpretation, and reviewing the manuscript. SW participated in data collection and input. LW made substantive intellectual contributions to the interpretation of data and drafts of the manuscript. All authors have read and approved the final manuscript. 


\section{Acknowledgements}

The authors would like to thank all the administrators in all selected universities for the organization of this survey and distribution of the questionnaires to the subjects. We also thank all the teachers for voluntarily participating in the study. Many thanks to Mr Shi for modifying the written English. However, this study was not supported by any external funding body.

Received: 2 June 2014 Accepted: 10 November 2014

Published online: 30 November 2014

\section{References}

1. Radloff LS: The CES-D scale: a self-report depression scale for research in the general population. Appl Psycho Meas 1977, 1:385-401.

2. Murray CJ, Lopez AD: Alternative projections of mortality and disability by cause 1990-2020: global burden of disease study. Lancet 1997, 349:1498-1504.

3. Park SG, Min KB, Chang SJ, Kim HC, Min JY: Job stress and depressive symptoms among Korean employees: the effects of culture on work. Int Arch Occup Environ Health 2009, 82:397-405.

4. Zhang J, Wu ZY, Fang G, LI J, Han BX, Chen ZY: Development of the Chinese age norms of CES-D in urban area. Chin Ment Health J 2010 24:139-144. in Chinese.

5. Scarth RD, Stallones L, Zwerling C, Burmeister LF: The prevalence of depressive symptoms and risk factors among lowa and Colorado farmers. Am J Ind Med 2000, 37:382-389.

6. Chou KL, Yu KM: Atypical depressive symptoms and obesity in a national sample of older adults with major depressive disorders. Depress Anxiety 2013, 30:574-579.

7. $\quad \mathrm{Lu} J$, Zhong $B \mathrm{~L}$, Chen $\mathrm{L}$ : The relationship between depressive and anxious emotion and turnover intention among nurses from tertiary general hospitals. Med J Chin People's Health 2013, 25:77-80 (in Chinese).

8. Papastylianou A, Kaila M, Polychronopoulos M: Teachers' burnout, depression, role ambiguity and conflict. Soc Psychol Educ 2009, 12:295-314

9. Ferguson K, Frost L, Hall D: Predicting teacher anxiety, depression, and job satisfaction. J Teach Learn 2012, 8:27-42

10. Tsai SY: A Study of the health-related quality of life and work-related stress of white-collar migrant workers. Int J Environ Res Public Health 2012, 9:3740-3754.

11. Mahan PL, Mahan MP, Park NJ, Shelton C, Brown KC, Weaver MT: Work environment stressors, social support, anxiety, and depression among secondary school teachers. AAOHN J 2010, 58:197-205.

12. Dragano N, He Y, Moebus S, Jockel KH, Erbel R, Siegrist J: Two models of job stress and depressive symptoms. Soc Psychiatry Psychiatr Epidemiol 2008, 43:72-78.

13. Buckner JD, Bernert RA, Cromer KR, Joiner TE, Schmidt NB: Social anxiety and insomnia: the mediating role of depressive symptoms. Depress Anxiety 2008, 25:124-130.

14. Tennant C: Work-related stress and depressive disorders. J Psychosom Res 2001, 51:697-704

15. Yang XJ, Yang X, Chen J, Zhang WY, Ma XH, Wang SH, Guo Z, Guo TW, Ma WH, Sun L, Wu Q, Tu Y: The correlation study between depressive state and life events of community residents in Beijing. Chin J Behav Med Brain Sei 2013, 22:1017-1019 (in Chinese).

16. Liu L, Chang Y, Fu J, Wang JN, Wang L: The mediating role of psychological capital on the association between occupational stress and depressive symptoms among Chinese physicians: a cross-sectional study. BMC Public Health 2012, 12:219.

17. Wu H, Ge CX, Sun W, Wang JN, Wang L: Depressive symptoms and occupational stress among Chinese female nurses: the mediating effects of social support and rational coping. Res Nurs Health 2011 34:401-407.

18. Vermeesch AL, Gonzalez-Guarda RM, Hall R, McCabe BE, Cianelli R, Peragallo NP: Predictors of depressive symptoms among Hispanic women in south Florida. West J Nurs Res 2013, 35:1325-1338.

19. Siegrist J: Adverse health effects of high-effort/low-reward conditions. J Occup Health Psychol 1996, 1:27.

20. Kinman $G$, Jones F: Effort-reward imbalance, over-commitment and worklife conflict: testing an expanded model. J Manag Psychol 2008, 23:236-251.

21. Sun W, Wu H, Wang L: Occupational stress and its related factors among university teachers in China. J Occup Health 2010, 53:280-286.
22. Winefield AH, Gillespie N, Stough C, Dua J, Hapuarachchi J, Boyd C: Occupational stress in Australian university staff: Results from a national survey. Int J Stress Manag 2003, 10:51

23. Zhao X, Liu L, Gao F, Wu H: Relationship among occupational stress, perceived organizational support and job satisfaction of the hospital nurses. J China Med Univ 2012, 41:764-765 (in Chinese).

24. Avey JB, Luthans F, Jensen SM: Psychological capital: a positive resource for combating employee stress and turnover. Hum Resour Manage 2009, 48:677-693.

25. Luthans F, Avolio BJ, Avey JB, Norman SM: Positive psychological capital: measurement and relationship with performance and satisfaction. Pers Psychol 2007, 60:541-572.

26. Luthans F, Youssef CM: Human, social, and Now positive psychological management: investing in people for competitive advantage. Organ Dyn 2004, 33:143-160

27. Yang $Y L$, Liu L, Wang XX, Wang Y, Wang L: Prevalence and associated positive psychological variables of depression and anxiety among Chinese cervical cancer patients: a cross-sectional study. PLoS One 2014, 9:1-9.

28. Rahimnia F, Mazidi AK, Mohammadzadeh Z: Emotional mediators of psychological capital on well-being: the role of stress, anxiety, and depression. Manage Sci Lett 2013, 3:913-926.

29. Wang Y, Chang Y, Fu JL, Wang L: Work-family conflict and burnout among Chinese female nurses: the mediating effect of psychological capital. BMC Public Health 2012, 12:915.

30. Luthans F, Norman SM, Avolio BJ, Avey AJ: The mediating role of psychological capital in the supportive organizational climateemployee performance relationship. J Organ Behav 2008, 29:219-238.

31. Lin TL: The relationships among perceived organization support, psychological capital and Employees' Job burnout in international tourist hotels. Life Sci J 2013, 10:2104-2112.

32. Cheung F, Tang CS, Tang SW: Psychological capital as a moderator between emotional labor, burnout, and job satisfaction among school teachers in China. Int J Stress Manag 2011, 18:348-371.

33. Shenyang Statistical Information Net. [http://www.sysinet.gov.cn/web/ tjnianjian/2013sy/15社会/15社会5.htm]

34. Li XY, Guo YS, Xia ZH: Association between Job stress and depressive symptom among civil servants. Chinese J Health Stat 2006, 23:499-501 (in Chinese).

35. Cho MJ, Nam JJ, Suh GH: Prevalence of symptoms of depression in a nationwide sample of Korean adults. Psychiatry Res 1998, 81:341-352.

36. Li J, Yang WJ, Cheng YW, Siegrist J, Cho Sl: Effort-reward imbalance at work and job dissatisfaction in Chinese healthcare workers: a validation study. Int Arch Occupy Environ Health 2005, 78:198-204.

37. Siegrist J, Starke D, Chandola T, Godin I, Marmot M, Niedhammer I, Peter R: The measurement of effort-reward imbalance at work: European comparisons. Socl Sci Med 2004, 58:1483-1499.

38. Zhang K, Zhang S, Dong YH: Positive psychological capital: measurement and its association with mental health. Stu Psychol Behav 2010, 8:58-64

39. Baron RM, Kenny DA: The moderator-mediator variable distinction in social psychological research: conceptual, strategic, and statistical considerations. J Pers Psychol 1986, 51:1173-1182.

40. Cohen J, Cohen P, West SG, Aiken LS: Applied Multiple Regression/Correlation Analysis for the Behavioral Sciences. Hillsdale (MI): Lawrence Erlbaum Associates; 2003

41. Wang SY, Ma SB LHS, Wu CP: Study on prevalence of mental subhealth and effect factors on the teachers of colleges and universities. Xian dai Yu fang Yi xue 2004, 31:320-321. in Chinese.

42. Chen L, Xu S, Liu J, Chai T, Chen H: Analysis on health risk factor appraisal of teachers in 5 universities in Hubei province. China Occup Med 2009, 36:442-443 (in Chinese).

43. Nourry N, Luc A, Lefebvre F, Sultan-Taieb H, Bejean S: Psychosocial and organizational work environment of nurse managers and self-reported depressive symptoms: cross-sectional analysis from a cohort of nurse managers. Int J Occup Med Environ Health 2014, 27:252-269.

44. Sui GY, Hu S, Sun W, Wang Y, Liu L, Yang XS, Wang L: Prevalence and associated factors of depressive symptoms among Chinese male correctional officers. Int Arch Occup Environ Health 2014, 87:387-395.

45. Wang JN, Sun W, Chi TS, Wu H, Wang L: Prevalence and associated factors of depressive symptoms among Chinese doctors: a cross-sectional survey. Int Arch Occup Environ Health 2010, 83:905-911. 
46. Gillespie NA, Walsh M, Winefield AH, Stough DC: Occupational stress in universities: staff perceptions of the causes, consequences and moderators of stress. Work Stress 2001, 15:53-72.

47. Wang JL, Smailes E, Sareen J, Schmitz N, Fick G, Pattern S: Three job-related stress models and depression: a population-based study. Soc Psychiatry Psychiatr Epidemiol 2012, 47:185-193.

48. Tzeng DS, Chung WC, Lin CH, Yang CY: Effort-reward imbalance and quality of life of healthcare workers in military hospitals: a crosssectional study. BMC Health Serv Res 2012, 12:309.

49. Cross G, Carroll D: Goodwill Under Stress: Morale in UK Universities. London: Association of University Teachers; 1990

50. Manthei R, Gilmore A, Tuck B, Adair V: Teacher stress in intermediate schools. Edu Res 1996, 38:3-9.

51. Abouserie R: Stress, coping strategies and job satisfaction in university academic staff. Edu Psychol 1996, 16:49-56.

52. Liu L, Hu S, Wang L, Sui GY, Ma L: Positive resources for combating depressive symptoms among Chinese male correctional officers: perceived organizational support and psychological capital. BMC Psychiatry 2013, 13:89.

53. Wang Y, Liu L, Wang JN, Wang L: Work-family conflict and burnout among Chinese doctors: the mediating role of psychological capital. $J$ Occup Health 2012, 54:232-240.

54. Luthans F, Avey JB, Patera JL: Experimental analysis of a web-based training intervention to develop positive psychological capital. AMLE 2008, 7:209-221.

55. Luthans F, Avey JB, Avolio BJ, Peterson SJ: The development and resulting performance impact of positive psychological capital. Hum Resource Dev Q 2010, 21:41-67.

56. Snyder CR: Handbook of Hope: Theory, Measures and Applications. New York: Academic Press; 2000

57. Seligman ME: Learned Optimism: How to Change Your Mind and Your Life. New York: Vintage; 2011.

58. Tugade MM, Fredrickson BL, Barrett LF: Psychological resilience and positive emotional granularity: examining the benefits of positive emotions on coping and health. J Pers 2004, 72:1161-1190.

59. Luthans F, Avey JB, Avolio BJ, Norman SM, Combs GM: Psychological capital development: toward a micro-intervention. J Organ Behav 2006, 27:387-393

doi:10.1186/s12888-014-0329-1

Cite this article as: Shen et al:: The association between occupational stress and depressive symptoms and the mediating role of psychological capital among Chinese university teachers: a cross-sectional study. BMC Psychiatry 2014 14:329.

\section{Submit your next manuscript to BioMed Central and take full advantage of:}

- Convenient online submission

- Thorough peer review

- No space constraints or color figure charges

- Immediate publication on acceptance

- Inclusion in PubMed, CAS, Scopus and Google Scholar

- Research which is freely available for redistribution 